\title{
Cytological Studies on three Species of Indian Spiders (Araneae: Pholcidae, Hersiliidae, Lycosidae)
}

\author{
Shiva Sharma and S. Ramakrishna \\ Department of Zoology, Jnanabharathi Campus, Bangalore University, \\ Bengaluru-560 065, Karnataka, India.
}

\begin{abstract}
Spiders (Arthropoda: Arachnida: Araneae) are fascinating and most diverse group of air breathing chelicerate arthropods in the animal kingdom. Their distribution is worldwide except Antartica and occupies every ecological niche available except of air and sea colonization. An improved air-dried method was to prepare spider chromosomes. Chromosome data are reported for 3 species belonging to families Pholcidae, Hersiliidae and Lycosidae from India. The number of diploid chromosomes ( $2 n)$ in both males and females and sex determining mechanism of each species were determined as follows: Crossopriza lyoni: $2 \mathrm{n}=23$ (XO ) male, Crossopriza lyoni: $2 \mathrm{n}=24(\mathrm{XX})$ female, Hersilia savignyi: $2 \mathrm{n}=30\left(\mathrm{X}_{1} \mathrm{X}_{2} \mathrm{O}\right)$ male, Hersilia savignyi: $2 \mathrm{n}=32 \quad\left(\mathrm{X}_{1} \mathrm{X}_{2} \mathrm{X}_{3} \mathrm{X}_{4}\right)$ female, Hippasa agelenoides: $2 \mathrm{n}=28 \quad\left(\mathrm{X}_{1} \mathrm{X}_{2} \mathrm{O}\right)$ male, Hippasa agelenoides: $2 \mathrm{n}=30\left(\mathrm{X}_{1} \mathrm{X}_{2} \mathrm{X}_{3} \mathrm{X}_{4}\right)$ female. During the first meiotic division 11, 14, 13 autosomal bivalents were found in Crossopriza lyoni, Hersilia savignyi and Hippasa agelenoides respectively. Crossopriza lyoni have metacentric and submetacentric type of chromosomes. In Hersilia savignyi chromosomes are acrocentric and rod shaped in Hippasa agelenoides.
\end{abstract}

Key words: Spiders, Cytological studies, Sex determining mechanism, Pholcidae, Hersiliidae, Lycosidae

\section{Introduction}

The order Araneae is divided into two suborders, Mesothelae and Opisthothelae. The later is divided into infra order Mygalomorphae and
Araneomorphae. The last infraorder is by far the most diverse and is divided into three groups: basal araneomorphs, haplogynae that groups spider with simple female genitalia and Entelegynae that includes spiders with more complex female genitalia (Coddington and Levi ${ }^{[1]}$ ) According to Platnick ${ }^{[2]}$, the order Araneae possesses 114 families, 3935 genera and 44,906 species. However currently there are 791 cytogenetic records in spiders from the world.

(www.arthropodacytogenetics.bio.br/spiderdatabase). Out of these, 2299 spider species belonging to 552 genera and 67 families are reported from South East Asia. Of the 552 genera, $49(9 \%)$ are monotypic, represented by single species and 65 genera (12\%) are endemic to one or more South Asian countries. About 1830 species $(80 \%)$ are endemic to South Asia. The most comprehensive description on spiders of 1066 species has been listed from fewer than 43 families, covering a number of species from various families distributed in different parts of India and also recorded 200 species from Burma and Srilanka $\left(\right.$ Tikader ${ }^{[3]}$ ).

Spiders represents a great diversity in male diploid numbers, which range from 7 (Suzuki ${ }^{[4]}$ ) to 128 (Kral et al. ${ }^{[5]}$ ). Karyotypes of 771 spider species belonging to 65 families have been reported up to now, majority of which is concerning Araneomorph spiders (Korinkova and Kral ${ }^{[6]}$; Araujo et al. ${ }^{[7]}$ ).

The evolution of multiple sex chromosomes in spiders is complicated and many hypotheses have been proposed (Aviles ${ }^{[8]}$.Another remarkable characteristic of spider chromosomes frequently shown is the presence of multiple sex chromosomes (White ${ }^{[9]}$ ). In spiders, 3 major types of sex 
determining mechanism have been reported, i.e. $\mathrm{XO}$, $\mathrm{X}_{1} \mathrm{X}_{2} \mathrm{O}$ and $\mathrm{X}_{1} \mathrm{X}_{2} \mathrm{X}_{3} \mathrm{O}$ types. All these types may have evolved from a remote XO-type ancestor by centric fragmentation accompanying inversion following breakage. The $\mathrm{X}_{1} \mathrm{X}_{2} \mathrm{X}_{3} \mathrm{O}$ type was derived from the $\mathrm{X}_{1} \mathrm{X}_{2} \mathrm{O}$ type by the same process described above and the modern XO-type evolved by the gradual elimination of one of the $2 \mathrm{X}$ s from the $\mathrm{X}_{1} \mathrm{X}_{2} \mathrm{O}$ type. However, the $\mathrm{X}_{1} \mathrm{X}_{2} \mathrm{O}$ type seems to be the most primitive in present day spiders as stated by Suzuki

$\left.{ }^{[4]}\right)$. Both chromosomes number and sex determining mechanism are important in the study of spiders phylogeny and mode of chromosome evolution.

The goal of the present research is to characterize each spider species by means of cytogenetic observations in order to evaluate each into the respective level of phylogeny. Karyotype information can be helpful in establishing the evolutionary relationships between species and for differentiating species that are otherwise similar.

\section{Material and methods}

Spiders were collected from natural habitat in Bangalore University Jnanabharathi campus, Bangalore, Karnataka, India. The specimens were identified following the keys of Sebastian and Peter $\left.{ }^{[10]}\right)$. The voucher specimen were preserved in $70 \%$ ethanol and deposited in Museum of Department of Zoology, Bangalore University, Bengaluru, Karnataka, India.

An Improved air-dried method (Luykx ${ }^{[11]}$ ) with some minor modifications was followed for preparing spider chromosomes. The spider was anesthetized and abdomen was cut open on wax plate using fine scissors. Gonads and gut epithelium were removed, placed on slides and soaked in 2 drops of $0.075 \mathrm{M}$ potassium chloride in a humid chamber for about 35min. Any excessive solution was removed from the slide and the tissues were fixed by adding few drops of fixative I (methyl alcohol: glacial acetic acid: water=3:3:4, by volume) across the inclined slide. With the slide lying flat, gonads were immediately macerated with fine needles and then 15 drops of fixative II (methyl alcohol: glacial acetic acid $=1: 1$, by volume) were added to the tissues. This fixative was allowed to stand for $15 \mathrm{~s}$, the slide was drained and placed in coupling jar containing fixative III (methyl alcohol: glacial acetic acid $=3: 1$, by volume) for $30 \mathrm{~min}$. The slide was removed and several drops of glacial acetic acid were added across the inclined slide after which the slide was flame dried. Chromosomes were stained by adding 10-15 drops of $5 \%$ Giemsa solution and were rinsed with distilled water. Mitotic chromosomes were subjected to $\mathrm{C}$ - banding (Sumner ${ }^{[12]}$ ) and NOR staining (Howell and Black, ${ }^{[13]}$ ) with minor modifications. Chromosome preparations were observed using Zeiss Axioskop 2 plus microscope and well spread complements were photographed.

\section{Results}

\section{$1 \quad$ PHOLCIDAE}

I. Crossopriza lyoni :- Mitotic metaphase cells of Crossopiza Lyoni showed a diploid number $2 \mathrm{n}=23(22 \mathrm{AA}+\mathrm{XO})$ in males and $2 \mathrm{n}=24(22 \mathrm{AA}+\mathrm{XX})$ in females with sex chromosomes system of $\mathrm{XO} / \mathrm{XX}$ type. The chromosomes are meta and submetacentric type. The autosomes pairs gradually decrease in size and the sex chromosome are extremely large. In females Pachytene cells presented 11 synapsed autosomal bivalents and two highly condensed and heavily stained univalent sex chromosomes. In the late stages of the prophase I, the X chromosome also revealed a higher degree of condensation in relation to the autosomes. 

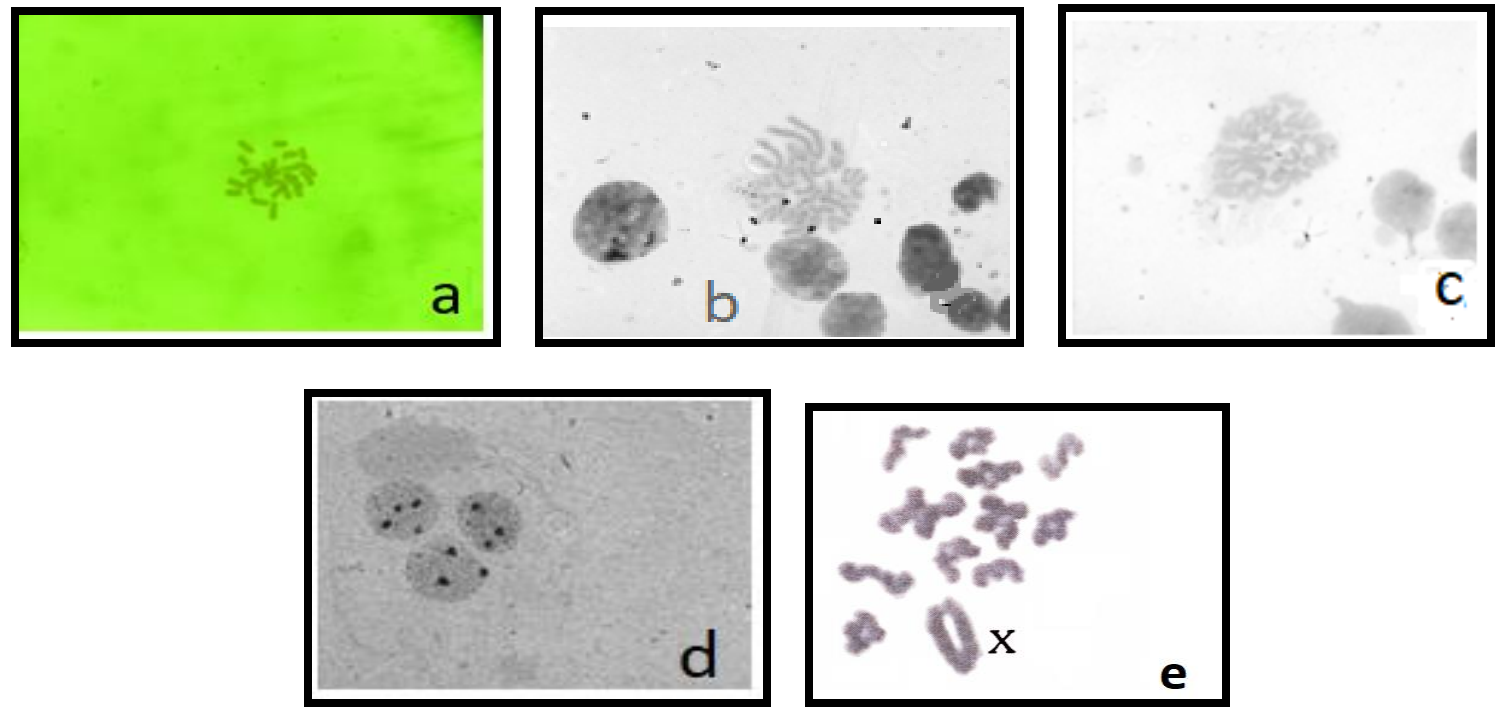

Fig.1 (a-e) Crossopriza lyoni : Gonadal mitotic metaphases from adult Crossopriza lyoni individuals. Conventionally Stained, male with $2 n=23$ and female with $2 n=24$. (a) metaphase complement (b, c) showing C bands (d) submitted to silver staining, NOR bearing chromosomes are indicated (e) Spermatocytes of adult. Crossopriza lyoni specimens in conventional staining-meiocyte in Prophase I with $2 \mathrm{n}=11$ bivalents $+\mathrm{X}$, showing the presence of metacentric and submetacentric chromosomes.

2

\section{HERSILIDAE}

I. Hersilia savignyi :- The diploid set of Hersilia savignyi has 30 chromosomes in mitotic preparations. Mitotic metaphase cells of Hersilia savignyi submitted to standard staining with Giemsa showed the diploid number $2 \mathrm{n}=30$ $\left(28 \mathrm{AA}+\mathrm{X}_{1} \mathrm{X}_{2}\right)$ in males which were consistent with the sex chromosome system $\mathrm{X}_{1} \mathrm{X}_{2} \mathrm{O}$ type. During prophase stages of meiotic division, sex chromosomes are more condensed and heavily stained than the autosomes. There are 14 bivalent autosomes and 2 sex chromosomes during diakinesis stage, indicating $\mathrm{X}_{1} \mathrm{X}_{2} \mathrm{O}$ sex chromosome system. C-Banding reveals that chromosomes are heavily stained in acrocentric region. The cells impregnated with silver nitrate shows the presence of many heterochromatic blocks in the interphase nuclei.
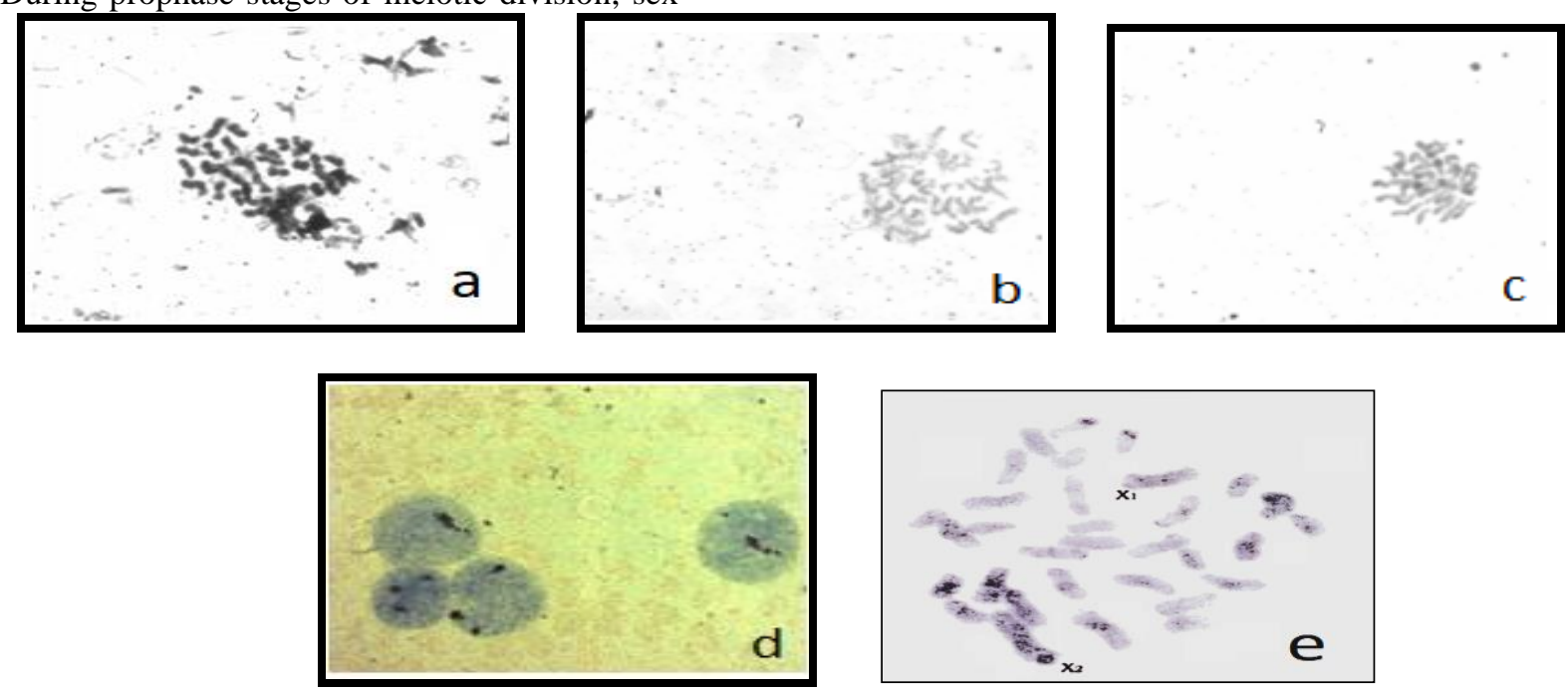
Fig.2 (a-e) Hersilia savignyi :- Testicular cells of Hersilia savignyi (a) Mitotic metaphase $2 \mathrm{n}=30$ (28AA + $\mathrm{X}_{1} \mathrm{X}_{2}$ ) and acrocentric chromosomes (b, c) C banding (d)submitted to silver staining, NOR bearing chromosomes are indicated (e)well spread chromosome plate showing $\mathrm{X}_{1} \mathrm{X}_{2}$. Giemsa-stained

\section{LYCOSIDAE}

I Hippasa aegelinoides :- The diploid chromosome mumber was determined to be $2 \mathrm{n}=28$ $\left(26 \mathrm{AA}+\mathrm{X}_{1} \mathrm{X}_{2}\right)$ in males as observed from well spread spermatogonial metaphase plates. All chromosomes are rod shaped with the sex determination system of
$\mathrm{X}_{1} \mathrm{X}_{2} \mathrm{O}$ type . Size difference is observed in the complements. The haploid number is 15 with 13 autosomes and two recognizable unequal rod shaped $\mathrm{X}$ elements. These $\mathrm{X}$ elements are not clearly distinguishable in spermatogonial metaphase but become conspicuous in subsequent stages of meiosis.
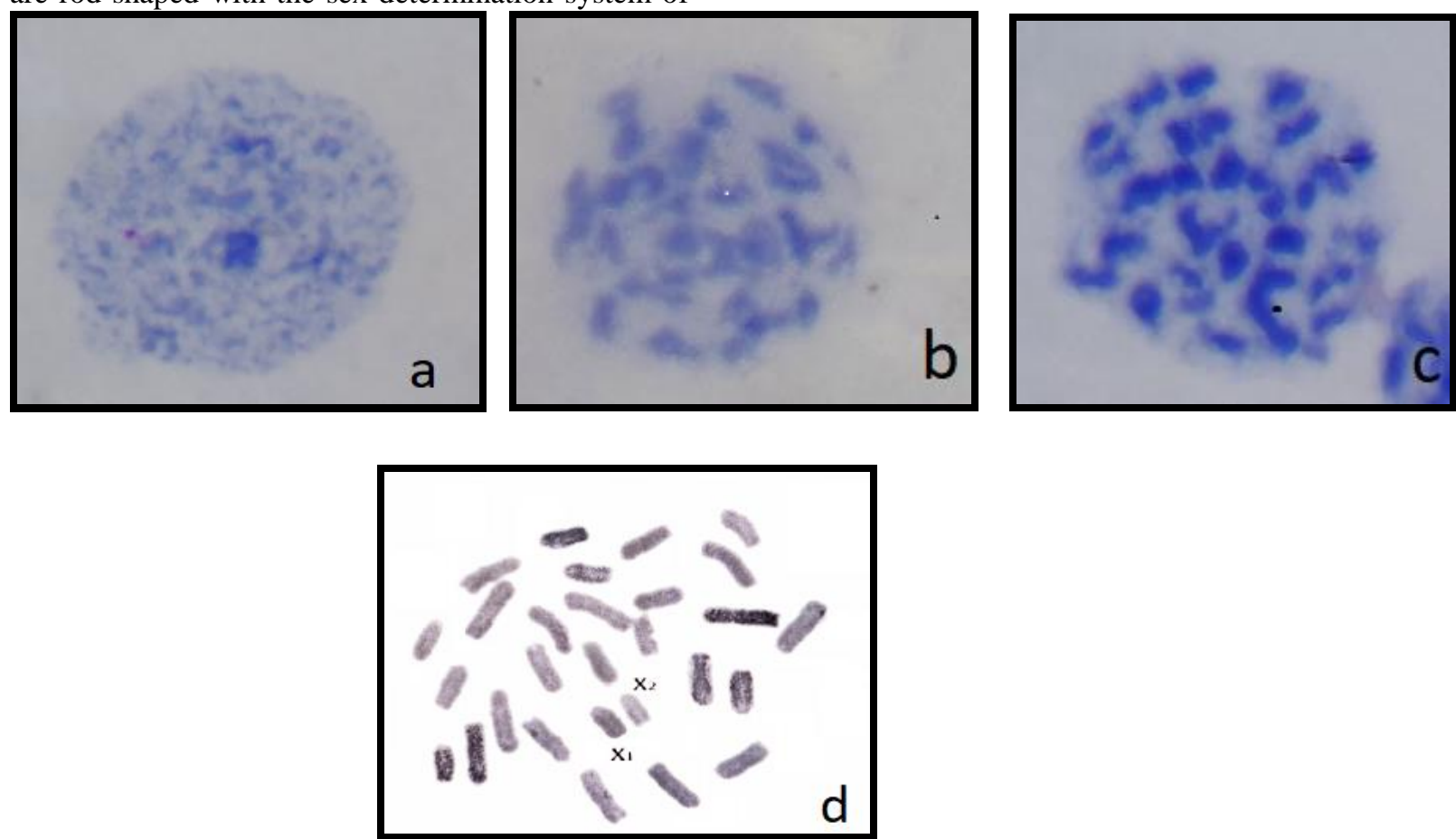

Fig.3 (a-d) Hippasa aegelinoides :- (a) Interphasic nuclei of male Hippasa species. Conventionally stained, showing a conspicuous heteropycnotic positive chromatinic block $(b, c)$ leptotene, Two heavily stained sex chromosomes in the margins of leptotene. (d) Spermatogonial mitotic metaphase plate $2 n=28$, showing the univalent sex chromosomes $\mathrm{X}_{1} \mathrm{X}_{2}$.

\section{Discussion}

Cytogenetic analysis of Indian spider species has added considerably to our knowledge about chromosomes in spiders and karyotypic evolution (Bole-Gowda ${ }^{[14]}$; Sharma et al ${ }^{[15]}$; Srivastava and Shukla ${ }^{[16]}$; Parida and Sharma ${ }^{[17]}$; Datta and Chatterjee ${ }^{[18]}$ ). BoleGowda ${ }^{[14]}$ presented the first karyotype for Indian Pholcid example, viz; C.lyoni depicting the diploid chromosome number $2 \mathrm{n}=27$ $(26 \mathrm{AA}+\mathrm{X})$ in males. Crossopriza lyoni chromosomal analysis showed that the diploid number $2 \mathrm{n}=23 \quad(22 \mathrm{AA}+\mathrm{X})$ in males predominantly meta and sub metacentric chromosomes by (Oliveira et al ${ }^{[19]}$ ) which matches with our study results. Presence of many heterochromatic blocks reveals different gene expression during course of development. The previously studied pholcid species have diploid number between $2 n=15$ and $2 n=32$ with meta and sub metacentric chromosomes (Cokendolpher ${ }^{[20]}$; Araujo et al ${ }^{[21]}$; Kr'al et al ${ }^{[22]}$. 
Great amount of work has been done for Indian pholcids (Bole-Gowda ${ }^{[14]}$ ). He asserted that $\mathrm{X}_{1} \mathrm{X}_{2} \mathrm{O}$ SCS originated from $\mathrm{XO}$ system in the ancestor of spiders by fission in the middle of the $\mathrm{X}$ chromosome producing an acentric chromosome segment that translocated to a super numerary centric fragment. He also analyzed the chromosome of Hersilia savignyi and found that diploid chromosome number is $2 n=30$ and SCS X1X2 with all acrocentric chromosomes. Sharma et al ${ }^{[15]}$ recorded $2 n=32$ (15 II +X1X2) with metacentric autosomes and acrocentric sex chromosomes.

$$
\text { Hersilia savignyi males show }
$$
chromosome diploid number of 30 and sex chromosome system of $\mathrm{X}_{1} \mathrm{X}_{2}$ type with all acrocentric chromosomes (Srivastava and Shukla ${ }^{[16]}$; Parida and Sharma ${ }^{[23]}$; Sharma and Parida ${ }^{[24]}$ ). Our present study also fits in with the above diploid chromosome number for the species. According to previous studies, the diploid chromosome number in lycosidae varies from 22 to 28 (Bole-Gowda [14]; Sharma and Tandon ${ }^{[25]}$ ) among which 28 is observed in majority of species. The sex chromosomes are unequal in length. Datta and Chatterjee [26, 27] proposed $\mathrm{X}_{1} \mathrm{X}_{2} \mathrm{O}$ system is found in lycosids. Our study found the diploid chromosome

\section{References}

[1] Coddington JA and Levi HW. "Systematics and evolution of spiders (Araneae)". Annu Rev Ecol Syst, 22(I):565-592, 1991.

[2] Platnick NI. "The world spider catalog, version 7.5. American Museum of Natural history, New York". online at:http://research.amnh.org/entomology/spiders/catalo g/index.html. 2014.

[3] Tikader PK. "Handbook of Indian Spiders Zoological Survey of India,Calcutta,India".pp.253, 1987.

[4] Suzuki S. "Cytological studies in spiders.III.S tudies on the chromosomes of fifty seven species of spiders belonging to seventeen families, withgeneral considerations on chromosomal evolution". Journal of Science Hiroshima University Series B, 15:23-36, 1954.

[5] Kr'al J, Korinkova T, Krkavcova L, Musilova J, Forman M, Herrera IMA, Haddad CR, Vitkova, M, number in males of Hippasa aegelinoides to be 28 with the sex determination system of $\mathrm{X}_{1} \mathrm{X}_{2} \mathrm{O}$ type which fits to some extent with the previous data. Crossopriza lyoni chromosomal analysis showed that the diploid number $2 \mathrm{n}=23$ $(22 \mathrm{AA}+\mathrm{X})$ and $2 \mathrm{n}=24(22 \mathrm{AA}+\mathrm{XX})$ in males and females respectively with sex chromosome system of $\mathrm{XO} / \mathrm{XX}$ type. In Hersilia savignyi $2 \mathrm{n}=$ $30\left(28 \mathrm{AA}+\mathrm{X}_{1} \mathrm{X}_{2}\right)$ in males and in Hippasa $2 n=28\left(26 \mathrm{AA}+\mathrm{X}_{1} \mathrm{X}_{2}\right)$ in males which were consistent with $\mathrm{X}_{1} \mathrm{X}_{2} \mathrm{O}$ sex chromosome system. These Karyological data are useful in explaining karyotypic evolution, sex chromosomes system and meiosis in araneomorph spiders.

\section{Acknowledgement}

The authors are thankful to Department of Zoology, Jnanabharathi Campus, Bangalore University, Bengaluru Karnataka, India for providing facilities and equipments for this research.

Henriques S, Vargas JGP, Hedin M. "Evolution of karyotype, sex chromosomes and meiosis in mygalomorph spiders (Araneae: Mygalomorphae)".Biological Journal of the Linnean Society, 109(2): 377- 408, 2013.

[6] Kořínková T and Král J. (2013) Karyotypes, sex chromosomes, and meiotic division in spiders. In: Nenwing W (Ed) Spider Ecophysiology, 159-171, 2013.

[7] Araujo D, Schneider MC, Paula -Neta E and Maria Cella D. "Sex chromosomes and meiosis in spiders : A review, meiosis - Molecular Mechanisms and cytogenetic diversity", Dr. Andrew Swan (Ed.), ISBN: 978-953-51-0118-5, 2012.

[8] Aviles L., "When is the sex ratio biased in social spiders? : Chromosome studies of embryos and male meiosis in Anelosimus species (Araneae, Therididae)". The Journal of Arachnology, 19: 126$135,1991$.

[9] White MJD. “Animal cytology and evolution". $3^{\text {rd }}$ Edition. William Clowes \& Sons, London. 961, 1973. 
International Journal of Advanced Scientific Research and Management, Volume 4 Issue 12, Dec 2019

[10] Sebastian TD and Peter KV. "Spiders of India, First edition, Universities press, Hyderabad, India". 572, 2009.

[11] Luykx P. "XO-XX sex chromosomes and Robertsonian variations in the autosomes of the wood-roach Cryptocercus punctulatus (Dictyoptera:Blattaria:Cryptocercidae)".

Entomol.Soc.Am 76:518-522, 1983.

[12]Sumner AT. A simple technique for demonstrating centromeric heterochromatin. Experimental Cell Research, 75: 304-305, 1972.

[13] Howell WM. and Black DA. "Controlled silver staining of nucleus organizer regions with a protective colloidal developer, a 1-step method". Experientia 36:1014-1015, 1980.

[14] Bole-Gowda BN. "A study of the chromosomes during meiosis in twenty-two species of Indian spiders". Proceedings of The Zoological Society of Bengal. 11: 69-108, 1958.

[15] Sharma GP, Gupta BL and Parshad R. "Cytological Studies on Indian spiders .III. An analysis of the chromosomes in male germ cells of spider Crossopriza lyoni (Blackwall), Fam Pholcidae". Research bulletin of Punjab University 10: 49-53. 1959.

[16] Srivastava MDL. and Shukla S. "Chromosome number and sex determining in forty-seven species of Indian spiders". Chromosome Information Service, 41: 23-26, 1986.

[17] Parida BB. and Sharma N.N. "Cytological studies on Indian spiders I. Meiosis in three species of wolf spiders (Lycosidae: Arachnida)". Caryologia, 40(1-2):89-97, $1987 b$.

[18] Datta SN. and Chatterjee K. "Meiotic behaviour of chromosomes in two higher web weaver spiders". Perspective in Cytology and Genetics, 7:851-860, 1992b.

[19] Oliveira M, Jesus AC, De Domingues A, Maria D, Universidade C, Claro R. and Butantan I. "Chromosomes of Crossopriza Lyoni (Blackwall 1867), Intraindividual numerical chromosome variation in Physocyclus globosus (Taczanowski
1874), and the distribution pattern of NORs (Araneomorphae: Haplogynae: Pholeidae)". The Journal of Arachnology, 35: 293-306, 2007.

[20] Cokendolpher JC. "Karyotypes of three spider species (Araneae: pholcidae: Physocyclus)". Journal of the New York Entomological Society 97:475-478, 1989.

[21] Araujo DDe, Brescovit AD, Rheims CA, Maria D, Universidade,C, Paulista E. and Sa UDe., "Chromosomal data of two pholcids (Araneae, Haplogynae): A new diploid number and the first cytogenetical record for the new world clade", The Journal of Arachnology, 33(2): 591-596, 2005.

[22] Kr'al J, Musilova J, St'ahlavsky F, Rezac M, Akan Z, Edwards RL, Coyle FA and Almerje CR. "Evolution of the karyotype and sex chromosome system in basal clades of araneomorph spiders (Araneae, Araneomorphae)". Chromosome Res, 14: 859-880, 2006.

[23] Parida BB and Sharma N.N. "Chromosome number, sex mechanism and genome size in 27 species of Indian spiders". Chromosome Information Service, 43:11-13, 1987a.

[24] Sharma N. and Parida B B. "Study of chromosomes in spiders from Orissa". Pranikee., 8: 71-76, 1987.

[25]Sharma GP and Tandon KK. "Studies on the chromosomes of the spiders Oxyopes ryvesii and Oxyopes sp (oxyopidae)". Proc.44 Indian Science Congress., III:334 (Abstract). 1957.

[26] Datta S.N. and Chatterjee K. "Study of meiotic chromosomes of four hunting spiders of north eastern India". Perspectives in Cytology and Genetics, 6: 414-424, 1989.

[27] Datta SN. and Chatterjee K. "Chromosomes and sex determination in three species of spinner spiders from northeastern India". Cell and Chromosome Research, 15(2): 64-69, 1992a. 